\title{
PEMBERDAYAAN PETANI DALAM OPTIMALISASI LAHAN BERBASIS KONSERVASI DI DESA SUKAMANTRI KECAMATAN TAMANSARI KABUPATEN BOGOR
}

\section{EMPOWERMENT OF FARMERS IN CONSERVATION BASED LAND OPTIMIZATION IN SUKAMANTRI VILLAGE, TAMANSARI DISTRICT, BOGOR REGENCY}

\author{
L Humaira 1a , F Maad 1, R Andriyanti ${ }^{1}$ \\ ${ }^{1}$ Fakultas Pertanian, Universitas Nusa Bangsa Bogor Jawa Barat \\ aKorespondensi: Linar Humaira; E-mail: linar.humaira@yahoo.com \\ (Diterima: 16-07-2019; Ditelaah: 17-07-2019; Disetujui: 08-09-2019)
}

\begin{abstract}
Based on agriculturanl potential in the Sukamantri village which reached 1.46 million hectares of paddy fields and fields, this village should have enormous agricultural potential. However, due to the condition of the land tends to have slope and close to area that have fairly high land movement, so that the potential of agriculture and its resources have not been optimized,this due to the low level of farmer's awareness and knowledge in buiding productive activities that can improve the family's economic welfare. The aim of this activity is to provide education on agricultural utilization through the development of optimal conservation-based farming, so that it can improve the family economy. The methode of implementing this activity is trhough counselling, demonstration and training. The result achieved were 15 participating farmers whose partially lower education fees on averages did not finish elementary shcool but had the ability to actively participate during the activity, it can be seen from the farmer's responsiveness in attendig counseling and during training and demontration practices in farming try to diversify planting vertically, wich is cultivated with crops. Making rorak between plant plot is a conservation technology that easily carried out by farmers. Farmers who expessed satisfacton with this activity as much as $60 \%$ and who expressed their satisfacton as much as $40 \%$. There needs to be guidance in further knowledge and ability to create the independence of the farmers.
\end{abstract}

Keywords : Agricultural land, conservation, empowerment, optimalization.

\begin{abstract}
ABSTRAK
Berdasarkan potensi pertanian yang ada di Desa Sukamantri yang mencapai 1.46 juta hektar luas lahan untuk sawah dan ladang, yang seharusnya desa ini memiliki potensi pertanian yang sangat besar. Namun dikarenakan kondisi lahan yang cenderung memiliki kemiringan dan berdekatan dengan wilayah yang memiliki pergerakan tanah yang cukup tinggi, sehingga potensi pertanian dan sumber dayanya belum teroptimalkan, hal ini dikarenakan masih rendahnya keterampilan dan pengetahuan petani dalam membangun kegiatan produktif yang dapat meningkatkan kesejahteraan ekonomi keluarga. Tujuan kegiatan ini adalah untuk memberikan edukasi pemanfaatan lahan melalui pengembangan usaha tani secara optimal berbasis konservasi, sehingga dapat meningkatkan perekonomian keluarga. Metode pelaksanaan kegiatan ini melalui penyuluhan, demontrsasi dan pelatihan. Hasil kegiatan adalah 15 orang petani peserta yang sebagian besar berpendidikan rendah rata-rata tidak tamat SD namun memiliki kemampuan berpartisifasi aktif selama kegiatan berlangsung, terlihat dari responsipnya petani dalam mengikuti penyuluhan maupun saat pelatihan yang terlibat langsung dalam praktek berusaha tani diversifikasi penanaman
\end{abstract}


secara verticultur yang ditumpangsarikan dengan tanaman pangan. Pembuatan rorak di antara petak pertanaman merupakan teknologi konsevasi yang mudah dilakukan oleh petani. Petani yang menyatakan puas dengan kegiatan ini sebanyak $60 \%$ dan sangat puas sebanyak $40 \%$. Perlu adanya pembinaan dalam pengetahuan dan ketrampilan lebih lanjut untuk menciptakan kemandirian para petani.

Kata kunci : Konservasi, lahan pertanian, optimalisasi, pemberdayaan.

Humaira, I., Maad, F., Firliyanti., Qamariah, N., (2019). Pemberdayan Petani Dalam Optimalisasi Lahan Berbasis Konservasi di Desa Sukamantri Kecamatan Tamansari Kabupaten Bogor. Jurnal Qardhul Hasan; Media Pengabdian kepada Masyarakat, 5(2), 7782.

\section{PENDAHULUAN}

Di Indonesia jumlah penduduk miskin paling banyak dijumpai di daerah pedesaan dan memiliki sumber penghidupan dari usaha tani. Problematika petani miskin yang semakin terdesak menggunakan lahan marginal akan menyebabkan petani terjebak dalam lingkaran setan yang saling memiskinkan. Petani miskin akan menggunakan lahan hanya untuk dapat memenuhi kebutuhan hidupnya tanpa mempertimbangkan daya dukung sumberdaya lahan tersebut. Penurunan kualitas sumberdaya lahan dan tingkat hidup petani disini dapat merupakan sebab dan akibat dari kemiskinan petani, sebab kemiskinan dapat merupakan sumber pencemar lingkungan (Miller, 1991). Sumberdaya lahan atau tanah merupakan sumberdaya alam yang semakin penting, selain karena luasannya yang sangat terbatas pemanfaatannya juga harus dilakukan sesuai dengan potensinya.

Desa Sukamantri Kecamatan Cijeruk Bogor yang berada pada koordinat 106.765697 BT /-6.647967 LS dengan ketinggian 540 meter dpl dan jenis tanah andosol. Desa ini memiliki jumlah penduduk 17.878 jiwa dengan jumlah kepala keluarga 4.878 yang tersebar di lebih di 15 RW dan 67 RT. Berdasarkan jenis pekerjaan di desa ini 0,60 persennya adalah petani dan buruh tani. Lahan didesa ini seluas 850.000 Ha berupa sawah, 610.000 Ha merupakan ladang atau tegalan, 1.760 .000 merupakan lahan perkebunan, dengan komoditas unggulan berdasarkan luas dan nilai produksi adalah padi sawah.

Padi yang secara umum merupakan tanaman pangan utama yang dihasilkan oleh setiap daerah di Indonesia, banyak tersebar luas hampir di seluruh Kecamatan. Selain padi yang tersebar di Kabupaten Bogor, jagung juga sebagai komoditi unggulan yang diproduksi oleh lahan-lahan pertanian di Kabupaten Bogor seperti wilayah Darmaga, Cisarua, Ciseeng, dan Gunung Sindur. Sementera untuk daerah-daerah tertentu yang memiiki iklim bagus untuk tanaman hias seperti wilayah Tamansari, Cijeruk, Ciawi, dan Tajurhalang memiliki potensi yang cukup besar sebagai pusat produksi dan pemasaran tanaman hias terbesar di Bogor

(https://www.kompasiana.com/.../menggal i-potensi-Kabupaten-Bogor, diunduh tanggal 22 Oktober 2017).

Berdasarkan data Kementerian Energi dan Sumber Daya Mineral Republik Indonesia, wilayah potensi gerakan tanah di Kabupaten Bogor Provinsi Jawa Barat bulan Oktober 2017, dari 22 Kecamatan yang berpotensi gerakan tanah salah satunya adalah Kecamatan yang berdekatan dengan Kecamatan Tamansari yaitu Kecamatan Cijeruk dengan Potensi Gerakan Tanah pada tingkat Menengah sampai Tinggi dan berpotensi Banjir Bandang/Aliran Bahan Rombakan. Terkait dengan perkembangan kondisi air tanah di Kabupaten Bogor tersebut, beberapa cekungan air tanah kritis secara umum memperlihatkan kondisi ketersediaan air tanah yang semakin 
menurun dari tahun ke tahun sebagai implikasi dari meningkatnya pengambilan air tanah untuk keperluan industri, domestik serta komersial. Langkah-langkah konservasi dan pengendalian pemanfaatan air bawah tanah oleh pemerintah daerah telah dilakukan dalam lima tahun terakhir untuk mengendalikan laju penurunan air tanah, terutama di cekungan air tanah kritis (RPJMD Pemerintah Daerah Kabupaten Bogor, 2014).

Setiap jenis tanah mempunyai sifat dan ciri tertentu dan berbeda satu dengan lainnya serta memiliki potensi dan kendala yang berbeda sehingga diperlukan input teknologi yang berbeda untuk suatu jenis penggunaan pertanian dan atau non pertanian. Karena alasan tersebut, penggunaan tanah perlu dikelola dengan baik, sesuai karakteristik dan potensi, kendala dan input teknologi spesifik lokasi yang diperlukan agar diperoleh produktivitas pertanian yang optimal dan berkelanjutan (Subardja, D.,S. Ritung, M. Anda Sukarman, E. Suryani, dan R.E. Subandiono, 2016). Konservasi adalah upaya-upaya pelestarian lingkungan akan tetapi tetap memperhatikan manfaat yang bisa didapatkan pada saat itu dengan cara tetap mempertahankan keberadaan setiap komponen-konponen lingkungan untuk pemanfaatan di masa yang akan datang. (www.pengertianku.net. diunduh pada tanggal 22 Oktober 2017).

Berdasarkan luas lahan di desa Sukamantri untuk sawah dan ladang/tegal yang mencapai 1.460 .000 hektar seharusnya desa ini memiliki potensi pertanian yang sangat besar. Potensi pertanian ini tidak akan optimal bila dibandingkan dengan persentase petani dan buruh tani yang hanya mencapai 0,60 persennya dibanding jenis pekerjaan lainnya. Untuk meningkatkan produktivitas petani dan buruh tani serta menjaga kelestarian lingkungan di desa yang berdekatan dengan daerah yang memiliki potensi gerakan tanah ini, maka masyarakat taninya perlu diberikan edukasi serta pemahaman melalui penyuluhan dan pelatihan yang berkaitan dengan optimalisasi lahan yang berbasis pada konservasi. Salah satu yang perlu dipertimbangkan dalam pengembangan masyarakat adalah bentuk partisipasi langsung untuk membantu memastikan masyarakat memiliki suara dalam apa yang yang terjadi pada mereka (Sue Kenny, Brian Mc Grath, and Rhondha Philips, 2018)

Berdasarkan permasalahan petani yang berada di sekitar Desa Sukamantri, maka solusi yang ditawarkan untuk pemecahan persoalan tersebut yaitu dengan edukasi melalui penyuluhan dan pelatihan secara demplot agar masyarakat tani memahami mengenai pemanfaatan lahan kurang produktif melalui pengembangan usaha tani secara optimal berbasis konservasi bagi masyarakat lokal sehingga dapat meningkatkan perekonomian keluarga.

Kegiatan ini bertujuan untuk meningkatkan pemahaman dan ketrampilan petani pada umumnya dalam optimalisasi memanfaatkan lahan pertanian. Diharapkan setelah mereka memahami dan meningkat keterampilannya maka akan terjadi peningkatan pendapatan dan kesejahteraan petani.

\section{MATERI DAN METODE}

Kegiatan pengabdian ini dilakukan pada petani di Desa Sukamantri Kecamatan Tamansari Kabupaten Bogor pada bulan Oktober 2017, metode pelaksanaan kegiatan dengan pendekatan penyuluhan, pelatihan dan melakukan demontrasi atau memperagakan secara langsung. Uraian kegiatan-kegiatannya berupa:

Penyuluhan tentang memberikan pemahaman mengenai konservasi, tujuan serta manfaat konservasi, Peningkatan kompetensi petani dalam optimalisasi penggunaan lahan berbasis konservasi, pengendalian biaya usaha tani dalam rangka optimalisasi penggunaan sumberdaya berbasis konservasi, penyuluhan upaya meningkatkan kompetensi petani dalam mengelola usaha tani lahan kering, serta upaya mengendalikan biaya usaha tani 
dengan memanfaatkan sumberdaya lahan secara optimal, melalui diversifikasi usaha tani

Pelatihan dilakukan dengan pemaparan materi yang kemudian secara langsung di demonstrasikan atau diperagakan bagaimana membuat teknik konservasi yang mudah dilakukan oleh petani. Teknik konservasi yang dipraktekan membuat rorak dengan tujuan untuk mengatasi aliran permukaan tanah, yang dibuat diantara pertanaman dengan ukuran $100 \mathrm{~cm}$ x $50 \mathrm{~cm}$ dan kedalaman $50 \mathrm{~cm}$ dengan jarak antar rorak 3 meter. Kemudian pada rorak tersebut difungsikan juga dengan membuat pertanaman vertikal sebagai salah satu upaya diversifikasi usaha. Evaluasi kegiatan yang dilakukan dengan tanya jawab dan evaluasi berupa kuesioner dari pelaksanaan kegiatan ini untuk melihat sejauh mana pemahaman petani atas materi yang telah disampaikan.

\section{HASIL DAN PEMBAHASAN}

Pada tahap awal kegiatan ini dilakukan sosialisasi program kerja yang diawali dengan mewawancara ke 15 orang petani peserta untuk melihat kondisi petani secara mendalam, serta untuk menentukan metode penyuluhan dan pelatihan yang mudah diterima oleh kondisi petani.

Kegiatan pengabdian masyarakat tani di desa Sukamantri Kecamatan Tamansari ini diikuti oleh 15 orang petani yang berstatus sebagai petani penggarap. Lahan yang mereka garap adalah lahan milik IPB, dengan kewajiban membayar dalam setahun didasarkan kepada kemampuan petani (rata-rata petani membayar Rp. 100.000,- per tahun). Rata-rata penguasaan lahan garapannya adalah seluas 0.25 ha lahan kering, yang umumnya mereka tanam berupa talas, singkong, pisang, dan sayuran seperti kecipir dan cabe. Pendidikan ratarata petani adalah tidak sekolah dan tidak tamat sekolah dasar, sebagian besar memiliki kemampuan membaca. Usaha tani yang mereka lalukan masih sangat sederhana dengan teknologi seadanya karena petani-petani ini belum memiliki kelompok tani sebagai wadah untuk mendapatkan dan bertukar informasi, pertanian masih bersifat subsistem hanya untuk memenuhi kebutuhan keluarga sehari-hari. Dari segi pemasaran hasil yang mereka dapatkan mereka jual melalui pengumpul yang datang ke lokasi. Untuk komoditi pisang mereka jual dihitung per tandan seharga $\mathrm{Rp}$ 50.000,- sementara untuk komoditi talas dan singkong mereka jual secara borongan.

Penyuluhan dilakukan dengan cara memberikan pemahaman kepada petani mengenai konsep dasar dari pengertian konsevasi itu sendiri serta kenapa konservasi itu perlu dilakukan, dan bagaimana cara menggali kompetensi yang dimiliki petani terkait dengan upaya meningkatkan ketrampilan petani dalam berusaha taninya. Memberikan pemahaman dalam metode membuat rorak sebagai salah satu metode untuk konservasi tanah dan air yang relative mudah dibuat oleh petani. Selain itu diberikan pemahaman atas pemanfaatan lahan dengan usaha tani secara penanaman vertikal dalam upaya meningkatkan produksi dan pendapatan petani. Penyuluhan dilakukan dengan menggunakan bahasa daerah (bahasa sunda) untuk memudahkan petani memahaminya, selain itu menggunakan bantuan banner yang memuat gambargambar teknik membuat rorak maupun pertanian secara vertikultur. Selama kegiatan berlangsung petani sangat antusias dalam mengikuti penyuluhan ini terlihat dari aktifnya beberapa petani yang ikut berdiskusi/berdialog selama kegiatan berlangsung. Berikut ini foto kegiatan saat penyuluhan berlangsung.

Gambar 1. Kegiatan Penyuluhan Pada Petani di Desa Sukamantri.

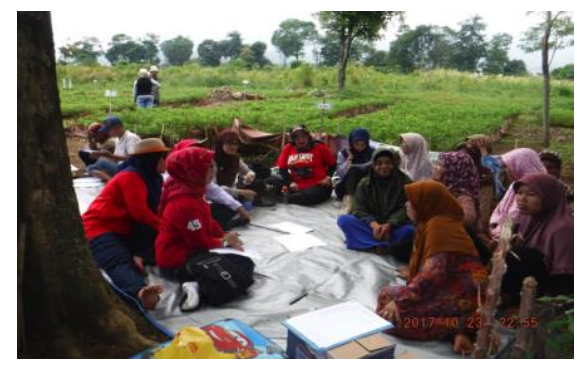


Gambar 2. Kegiatan Penyuluhan Pada Petani di Desa Sukamantri.

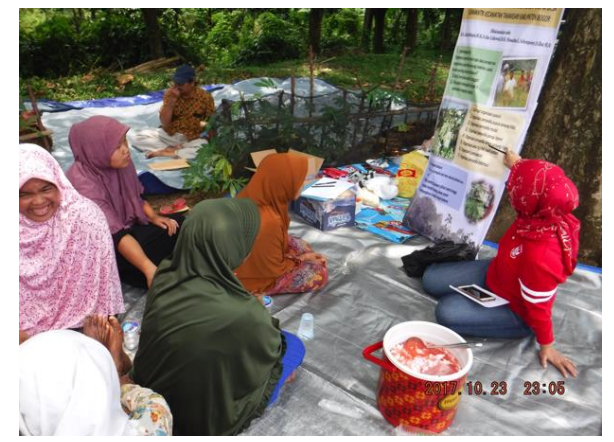

Setelah penyuluhan dilanjutkan dengan kegiatan pelatihan. Teknik pelatihan dilakukan dengan mendemonstrasikan atau mempraktekan secara langsung bagaimana membuat rorak pada lahan pertanian sebagai salah satu upaya bentuk konservasi tanah dan air. Setelah itu mempraktekan pemanfatan lahan secara optimal dengan pertanaman sisipan dengan teknik pertanian vertikal yang menggunakan paralon berukuran 1 meter dengan jarak penanaman $50 \mathrm{~cm} \times 50 \mathrm{~cm}$, sehingga dalam satu batang paralon bisa ditanami 2 - 4 tanaman. Tanaman yang ditanam secara vertikal yaitu tanam cabe, tanaman secara vertikal ini dapat ditanam sebagai alternatif tanaman tumpangsari dengan komoditi utamanya tanaman pangan, dalam praktek ini ditanam diantara tanaman kacang tanah. Dari hasil kegiatan ini teknik penanaman secara vertikal ini, dapat dipraktekan petani di sekitar halaman rumah sehingga diharapkan dapat membantu memenuhi kebutuhan pangan keluarga. Berikut ini adalah foto-foto kegiatan pelatihan dengan mempraktekan secara langsung membuat rorak dan pertanaman vertikultur dalam rorak yang disipkan pada pertanaman tanaman pangan.
Gambar 3. Demo dan Pelatihan Pertanian Verticultur Pada Rorak yang disiapkan dengan Tanaman Pangan.

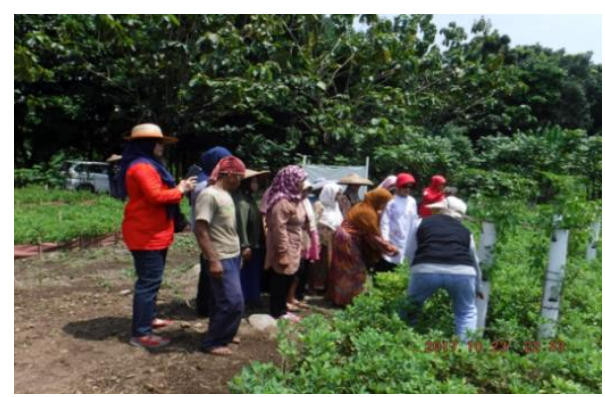

Gambar 4. Demo dan Pelatihan Pertanian Verticultur Pada Rorak yang disipkan dengan Tanaman Pangan.

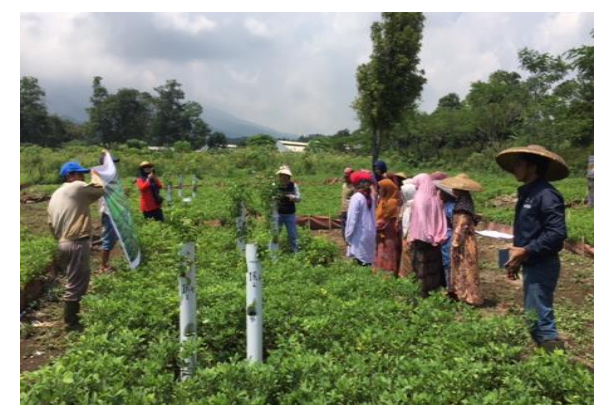

Kegiatan terakhir dilakukan evaluasi secara bersama-sama antara petani peserta dengan team, dilakukan tanya jawab dan evaluasi secara tertulis. Hasil evaluasi petani memberikan tanggapan yang sangat positif yaitu dengan terlihatnya antusias petani dalam berdialog atau tanya jawab. Hasil evaluasi tertulis $60 \%$ petani menyatakan merasa puas dan $40 \%$ nya petani menyatakan sangat puas dengan kegiatan ini. Karena Petani belum memiliki kelompok sehingga petani menginginkan untuk dibentuknya kelompok tani agar memudahkan mereka dalam berbagi informasi serta adanya pertemuan rutin. Kegiatan ini diakhiri dengan sesi foto bersama petani dan Team dari UNB. 
Gambar 5. Evakuasi Kegiatan.

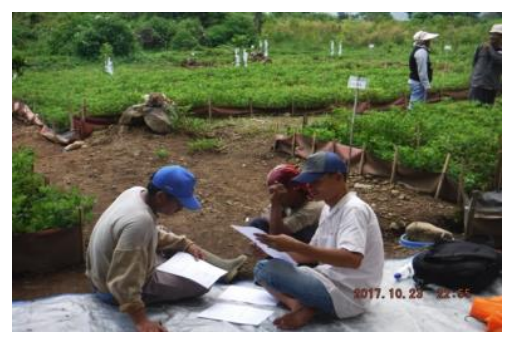

Gambar 6. Evakuasi Kegiatan

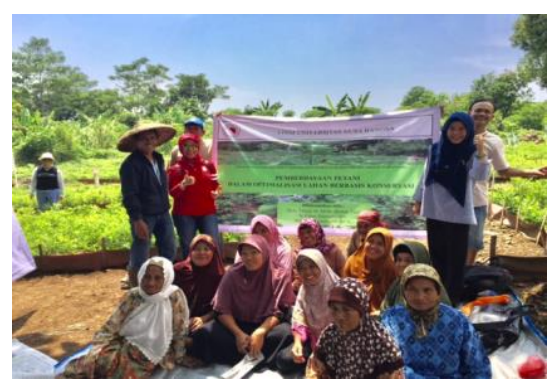

\section{KESIMPULAN}

Pelaksanaan kegiatan penyuluhan dan pelatihan ini masih belum optimal, disebabkan oleh beberapa faktor yaitu: 1) Kondisi sosial ekonomi petani yang rendah 2) Hampir $50 \%$ sudah bukan usia produktif, 3) Status petani hanya sebagai petani penggarap dengan luasan penguasaan ratarata $0,25 \mathrm{Ha}, 4)$ terbatasnya fasilitas fisik (sarana dan prasarana) dalam pelaksanaan usaha tani. Meskipun demikian petani merasa puas dengan adanya kegiatan edukasi ini, hal ini terlihat dari antusiasnya petani selama kegiatan berlangsung dan pernyataan petani $60 \%$ merasa puas dan $40 \%$ sangat puas. Metode rorak merupakan salah satu teknologi konservasi tanah dan air yang relative mudah dilakukan oleh petani, penanaman tanaman pangan dengan sisipan pertanaman vertikultur adalah sebagai upaya diversifikasi produk untuk meningkatkan pendapatan petani.

Dari kegiatan ini yang dapat disarankan bagi petani di Desa Sukamantri Kecamatan Tamansari ini perlu adanya pembinaan dalam pengetahuan dan ketrampilan lebih lanjut untuk menciptakan kemandirian para petani, perlu dibentuknya kelompokkelompok kecil agar tercipta untuk saling bertemu serta bertukar pikiran dan pengalaman diantara para petani. Upaya ini akan sangat membantu dalam penyelesaian permasalahan teutama bagi mereka yang mengalami masalah yang sama.

\section{DAFTAR PUSTAKA}

https://www.kompasiana.com/.../menggalipotensi-Kabupaten-Bogor diunduh pada tanggal 22 Oktober 2017.

Miller, GT. 1991. Environmental Science: Sustaining the Earth. Wadsworth Publishing Company. Belmont, California.

Naik Sinukaban, 2007. Konservasi Tanah dan Air Kunci Pembangunan Berkelanjutan. Direktotar Jenderal RLPS.

RPJMD Kabupaten Bogor Tahun 2013-2018, Pemerintah Daerah Kabupaten Bogor, 2014.

www.pengertianku.net, diunduh pada tanggal 22 Oktober 2017.

Subardja, D.,S. Ritung, M. Anda Sukarman, E. Suryani, dan R.E. Subandiono. 2016. Petunjuk Teknis Klasifikasi Nasional. Edisi ke-2. Balai Besar Penelitian dan Pengembangan Sumberdaya Lahan Pertanian, Badan Penelitian dan Pengembangan Pertanian, Bogor. 60 Hal.

Sukarman, Sofyan Ritung, Markus Anda, Erna Suryani. 2017. Pedoman Pengamatan Tanah Di Lapangan. Balai Penelitian dan Pengembangan Pertanian, Kementerian Pertanian. Jakarta.

Sue Kenny, Brian Mc Grath, and Rhondha Philips. 2018. The Routledge Handbook of Community Development Perspectives From Arround The Globe. New York and London. 